\title{
Viability of the microencapsulation of a casein hydrolysate in lipid microparticles of cupuacu butter and stearic acid
}

\author{
Janaina C. Silva and Samantha C. Pinho* \\ Department of Food Engineering, School of Animal Science and Food Engineering, University of São Paulo (USP), \\ Avenida Duque de Caxias Norte, 225 - Jd. Elite - Pirassununga, SP, Brazil, 13635-900. \\ ${ }^{*}$ Corresponding author \\ samantha@usp.br \\ TEL: $(+55-19) 3565-4288$ \\ FAX: (+55-19) 3565-4284
}

Received: 22 May 2012; Published online: 18 April 2013

\begin{abstract}
Solid lipid microparticles produced with a mixture of cupuacu butter and stearic acid were used to microencapsulate a commercial casein hydrolysate (Hyprol 8052). The composition of the lipid matrix used for the production of the lipid microparticles was chosen according to data on the wide angle X-ray diffraction (WAXD) and differential scanning calorimetry (DSC) of bulk lipid mixtures, which indicated that the presence of $10 \%$ cupuacu butter was sufficient to significantly change the crystalline arrangement of pure stearic acid. Preliminary tests indicated that a minimum proportion of $4 \%$ of surfactant (polysorbate 80) was necessary to produce empty spherical lipid particles with average diameters below $10 \mu \mathrm{m}$. The lipid microparticles were produced using $20 \%$ cupuacu butter and $80 \%$ stearic acid and then stabilized with $4 \%$ of polysorbate 80 , exhibiting an encapsulation efficiency of approximately $74 \%$ of the casein hydrolysate. The melting temperature of the casein hydrolysate-loaded lipid microparticles was detected at $65.2^{\circ} \mathrm{C}$, demonstrating that the particles were solid at room temperature as expected and indicating that the incorporation of peptides had not affected their thermal behavior. After 25 days of storage, however, there was a release of approximately $30 \%$ of the initial amount of encapsulated casein hydrolysate. This release was not thought to have been caused by the liberation of encapsulated casein hydrolysate. Instead, it was attributed to the possible desorption of the adsorbed peptides present on the surface of the lipid microparticles.
\end{abstract}

Keywords: Casein hydrolysate, solid lipid particles, microencapsulation.

\section{Introduction}

The hydrolysis of proteins can originate in the bioactive peptides, which are defined as specific protein fragments whose ingestion has a positive impact on physiological functions (Korhonen, 2009; Kitts \& Weiler, 2003). Several health benefits have been attributed to these hydrolysates: e.g., blood pressure-lowering and cholesterol-lowering abilities, antimicrobial actions, antithrombotic effects and the enhancement of mineral absorption, cyto- or immuno-modulatory effects, and opioid activities (Agyei \& Danquah, 2012; Cam \& de Mejia, 2012; Korhonen, 2009; Lopez Exposito \& Recio, 2006; Gauthier, Pouliot, \& Saint-Sauveur, 2006; Mikkelsen, Rasmussen, Olsen, Barkholt, \& Frokiaer, 2006; Pan et al., 2006; Mercier, Gauthier, \& Fliss, 2004; Clemente, 2000; Hartmann \& Meisel, 2007). Another important use of bioactive peptides is in support of the specific clinical needs of patients with phenylketonuria, acute and chronic liver disease, Crohn's disease, pancreati- 
tis and ulcerative colitis (Almeida \& Souto, 2007; Clemente, 2000). In particular, casein hydrolysates have been extensively studied due to their antihypertensive, anti-inflammatory, immunomodulatory and antimicrobial actions (Agyei \& Danquah, 2012; Espeche Turbay, de Moreno de LeBlanc, Perdigon, Savoy de Giori, \& Hebert, 2012; Nakamura et al., 2011; del Mar Contreras, Carron, Jose Montero, Ramos, \& Recio, 2009).

However, protein hydrolysates typically have unpleasant sensory properties (pronounced bitterness and strong odor) and the difficulty of dispersing them in aqueous formulations due to their hydrophobicity may limit the possibilities of their addition to food products. Some additional disadvantages of these bioactives are their high hygroscopicity, high reactivity and high risk of allergenicity upon ingestion (Favaro-Trindade, Santana, Monterrey-Quintero, Trindade, \& Netto, 2010; Molina Ortiz et al., 2009; Clemente, 2000). In addition, many researchers have noted that the bioavailability of peptides after oral administration may be extremely low due to their instability in the gastrointestinal tract and their low permeability through the intestinal membrane (Moutinho, Matos, Teixeira, \& Balcao, 2012; Dai, Wang, \& Zhao, 2005; Lee \& Yamamoto, 1989). The bioavailability of bioactive compounds is extremely dependent on a molecular mass below $700 \mathrm{Da}$; beyond this limit, their bioavailability decreases sharply (Moutinho et al., 2012). There is also a minimum level of hydrophicity required for the macromolecules' permeation through the intestinal epithelium and their passive diffusion. The typical absolute oral bioavailability of most particles is lower than 1 \% (Moutinho et al., 2012; Shaji \& Patole, 2008).

Microencapsulation technologies are excellent options to overcome some of the problems described above - high hygroscopicity, high reactivity, and poor sensorial characteristics (Yokota, Moraes, \& Pinho, 2012; Favaro-Trindade et al., 2010; Molina Ortiz et al., 2009) - and to improve the peptides' resistance to gastrointestinal conditions and enhance their absorption in the intestine (Agyei \& Danquah, 2012; Korhonen, 2009). The encapsulation of peptides in micro- or nano-sized structures can improve their delivery capacity and decrease the difficulty of their transport across membranes, especially if lipid-based matrices are used in the encapsulation systems (Agyei \& Danquah, 2012). Some frequently used structured lipid-based delivery systems are lipid droplets (emulsions, microemulsions, nanoemulsions, and multiple emulsions), liposomes, coated particles (multilayer emulsions or colloidosomes), and solid lipid particles (McClements, 2010; McClements \& Li, 2010). Solid lipid particles can be described as an emulsion whose liquid core was replaced by a solid lipid (lipids that are solid at room temperature) (Muller, Radtke, \& Wissing, 2002; Mehnert \& Mader, 2001; Muller, Mader, \& Gohla, 2000). Among the advantages of using these particles to load active ingredients are their full biodegradability and biocompatibility and their high capacity for incorporating hydrophobic compounds. In addition, they can be engineered to allow the controlled release of the bioactive ingredient and protect the sensitive and labile molecules from degradation, using processes that can be scaled up and that employ no organic solvents (Fathi, Mozafari, \& Mohebbi, 2012; Moutinho et al., 2012). Solid lipid particles are an extremely interesting delivery system with multiple potential applications in the food industry. They are of particular interest to the manufacturers of functional foods who are seeking novel ways to include lipophilic but chemically sensitive bioactive compounds (Weiss et al., 2008). Solid lipid particles are also of great interest in the pharmaceutical field for the encapsulation of proteins and peptides, as attested by numerous papers cited by Moutinho et al. (2012) and Almeida and Souto (2007).

The main aim of this investigation was to produce solid lipid microparticles composed of cupuacu butter and stearic acid for the encapsulation of a commercial casein hydrolysate (Hyprol 8052). Cupuacu butter was chosen for two primary reasons:

1. it is an important industrial product, especially in Brazil, and

2. it is low in palmitic acid, which is known to raise cholesterol levels, and rich in stearic acid, which is neutral in that regard (Silva et al., 2009; Osborn \& Akoh, 2002).

Stearic acid was also chosen because it is a longchain fatty acid that is not absorbed by the gastrointestinal tract (Lairon, 2009; Osborn \& Akoh, 
2002). Before producing the particles, bulk lipid mixtures of both raw materials were produced and evaluated to choose the best combination to produce the dispersions. The lipid microparticles were produced by ultra-agitation and stabilized with polysorbate 80 , a surfactant commonly used in the food industry. Preliminary tests with different mass percentages of cupuacu butter and polysorbate 80 were conducted to select the particle formulation with the lowest average particle diameter. The shelf life of the chosen formulation of lipid microparticles was analyzed in terms of the particles' casein hydrolysate retention and their size distributions.

\section{Experimental}

\subsection{Chemicals}

The cupuacu (Theobroma grandflorum) butter (obtained from cupuacu beans), hereby referred to as CB, was a donation from Croda (Campinas, Brazil). The composition of this butter was determined by gas chromatography and according to the official methods of the AOCS (1-62 and 2-66) (AOCS, 1998). It is described in Table 1.

This fatty acid profile is in accordance with the findings of previous authors (Saraiva, Cabral, Eberlin, \& Catharino, 2009; Silva et al., 2009; Lannes, Medeiros, \& Gioielli, 2004), who also concluded that stearic and oleic acids were the most abundant fatty acids in cupuacu butter. Saraiva et al. (2009) analyzed cupuacu butter via mass spectrometry and determined that the most abundant triacylglycerols in this fat are SSO $(\sim 30 \%)$, OOS+SSL $(\sim 20 \%)$, ASO $(\sim 13 \%)$ and POS $(\sim$ $10 \%$ ) where $\mathrm{S}=$ stearic acid, $\mathrm{O}=$ oleic acid, $\mathrm{A}=$ arachidonic acid and $\mathrm{P}=$ palmitic acid).

The stearic acid (SA) was obtained from Sigma (St Louis, USA). Polysorbate 80 (PS80) was obtained from Synth (Diadema, Brazil). Hyprol 8052 (casein hydrolysate) was donated by Kerry Bioscience (Campinas, Brazil), and its amino acid composition is presented in Figure 1. Hyprol 8052 also contains $9 \%$ casein phosphopeptides (CPP) and $21 \%$ free amino acids, and $92 \%$ of the peptides have a molecular weight below $5 \mathrm{kDa}$. All other reagents and organic solvents were of analytical grade. Deionized

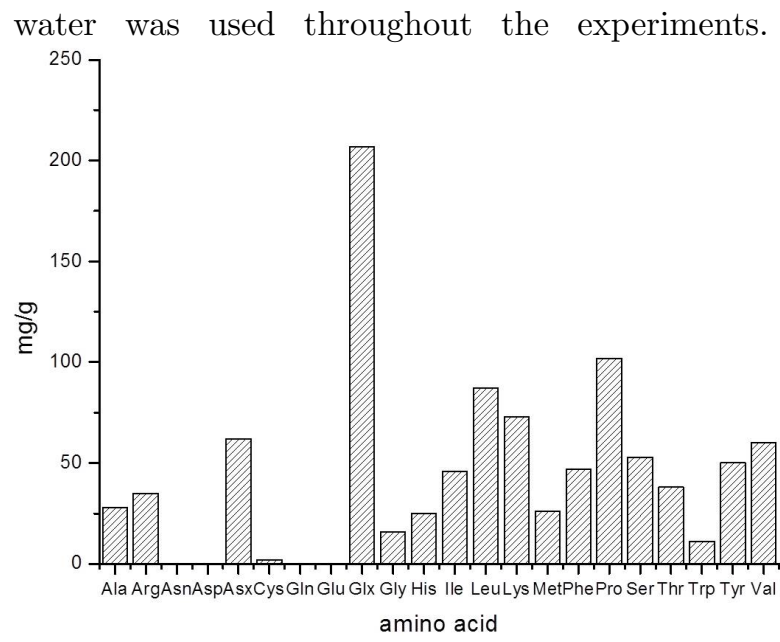

Figure 1: Amino acid composition of casein hydrolysate (Hyprol 8052) (Source: Kerry Bioscience, 2005). Glx (glutamate+glutamic acid): 21 \%; proline: $10.2 \%$; leucine: $8.7 \%$; lysine: $7.3 \%$ (\% mass).

\subsection{Production of bulk lipid matrices}

Lipid mixtures containing 10 and $25 \%$ (mass percentage) $\mathrm{CB}$ with SA making up the remaining mass were prepared by the fusion of the two components at $80^{\circ} \mathrm{C}$ in a water bath. After fusion, the samples were kept at room temperature until completely cooled and solidified.

\subsection{Production of lipid microparticles and evaluation of encapsulation efficiency}

Lipid microparticles (LM) were produced by melting the lipid phase at, according to the formulations described in Table 2. The hot surfactant solution (polysorbate 80 ) at $80^{\circ} \mathrm{C}$ was mixed with the melted lipid and submitted to ultra-agitation (IKA T25, IKA, Germany) at 8,000 rpm for 5 min. In formulations containing the casein hydrolysate, it was added to the surfactant solution to produce a final dispersion containing $1 \mathrm{~g}$ casein hydrolysate $\cdot \mathrm{L}^{-1}$. The emulsion systems were then magnetically stirred and cooled in an ice bath to 20 ${ }^{\mathrm{o}} \mathrm{C}$. The dispersions of lipid particles were stored 
Casein hydrolysate in lipid particles $\mid 51$

Table 1: The fatty acid composition of cupuacu (Theobroma grandflorum) butter used in this study.

\begin{tabular}{cccc}
\hline \multicolumn{2}{c}{ Compound } & $\%$ area & S.D. \\
\hline C16:0 & palmitic & 7.46 & 0.31 \\
C16:1 & palmitoleic & 0.07 & n.a. $^{*}$ \\
C17:0 & margaric & 0.16 & n.a. \\
C18:0 & stearic & 31.55 & 0.35 \\
C18:1 c,t & oleic & 42.54 & 0.21 \\
C18:2 c & linoleic & 5.86 & 0.05 \\
C18:3 alpha & $\alpha$-linolenic & 0.16 & n.a. \\
C20:0 & arachidic & 10.02 & 0.41 \\
C20:1 c & gadoleic & 0.35 & 0.01 \\
C22:0 & behenic & 1.61 & 0.11 \\
C24:0 & lignoceric & 0.23 & 0.01 \\
\hline \multicolumn{4}{c}{${ }^{*}$ n.a. = not available }
\end{tabular}

Table 2: Particle formulations produced in this study.

\begin{tabular}{ccccc}
\hline Particle & $\begin{array}{c}\text { Stearic Acid } \\
(\%)\end{array}$ & $\begin{array}{c}\text { Cupuacu butter (\%) } \\
\text { Polysorbate 80 } \\
(\%)\end{array}$ & Deionized water \\
\hline 10 CB-2 & 2.70 & 0.30 & 2 & q.s. $100 \mathrm{~mL}$ \\
15 CB-2 & 2.55 & 0.45 & 2 & q.s. $100 \mathrm{~mL}$ \\
15 CB-4 & 2.55 & 0.45 & 4 & q.s. $100 \mathrm{~mL}$ \\
20 CB-2 & 2.40 & 0.60 & 2 & q.s. $100 \mathrm{~mL}$ \\
20 CB-4 & 2.40 & 0.60 & 4 & q.s. $100 \mathrm{~mL}$ \\
\hline
\end{tabular}

under refrigeration $\left(7-10^{\circ} \mathrm{C}\right)$.

Nonencapsulated casein hydrolysate was separated by ultrafiltration through a cellulose membrane (cut-off molecular weight of 100 kDa, YM100, Mil- lipore) and quantified for total protein using the Lowry method as modified by Peterson (1979). The encapsulation efficiency was determined by the following equation:

$$
E E(\%)=100 * \frac{\text { original mass of } C H \text { in the surfactant solution-mass of non encapsulated } C H}{\text { original mass of } C H \text { in the surfactant solution }}
$$

\subsection{Determination of particle size distribution}

The particle size distribution was determined by laser diffraction using the Sald-201V (Shimadzu Corporation, Japan) equipment at $25{ }^{\circ} \mathrm{C}$. The samples were diluted with ultra-pure water before the measurements.

\subsection{Thermal behavior by differential scanning calorimetry (DSC)}

The bulk lipid mixtures were analyzed in a microcalorimeter (TA2010, controlled by the TA5000 system, both from TA Instruments, USA) with a temperature ramp of $10^{\circ} \mathrm{C} \cdot \mathrm{min}^{-1}$ in an inert at- 
mosphere $\left(45 \mathrm{~mL} \cdot \mathrm{min}^{-1}\right.$ of $\mathrm{N}_{2}$ ). The reference was an empty aluminum pan. The onset and melting (peak) temperatures were calculated using Universal Analysis V.7 software (TA Instruments). The crystallization index (CI) was calculated according to the following expression:

$$
\mathrm{CI}(\%)=\frac{\text { enthalpy LM }}{\text { enthalpy PL }} * \mathrm{FM} * 100
$$

where enthalpy LM is the melting enthalpy of the lipid mixture, enthalpy PL is the melting enthalpy of the pure lipid and fM is a factor that takes the concentration of solid lipid in the matrix into account (0.90 or 0.75 for mixtures containing 90 and $75 \%$ solid lipid, respectively, in the case of stearic acid) (Severino, Pinho, Souto, \& Santana, 2011; Junyaprasert, Teeranachaideekul, Souto, Boonme, \& Mueller, 2009).

DSC analyses of the liquid dispersions of LM were conducted with scans at temperatures ranging from 40 to $110^{\circ} \mathrm{C}\left(0.5^{\circ} \mathrm{C} . \mathrm{min}^{-1}\right)$ in a N-DSC III (Calorimetry Sciences Corp., USA); deionized water was used as a reference.

\subsection{Analysis of particle morphology by scanning electron microscopy (SEM)}

Scanning electron microscopy of LM was performed using a LEO 440i (Leica Instruments, Germany) with an accelerating voltage of $15 \mathrm{kV}$. Single samples of different formulations were first dried in a desiccator and then sputtered with gold in a Pelaron SC7620 sputter coater (Ringmer, UK) at a covering rate of 0.51 angstrons.s ${ }^{-1}$ for $180 \mathrm{~s}$, using a current of $3-5 \mathrm{~mA}, 1 \mathrm{~V}$ and at a pressure of $2 \times 10^{-2} \mathrm{~Pa}$.

\subsection{Analysis of crystallinity by wide angle $\mathrm{X}$-ray diffraction (WAXD)}

Both bulk lipid mixtures were analyzed using an Xray diffractometer (Phillips $\mathrm{X}^{\prime} \mathrm{PERT}$, copper anode, $\lambda=1.5418$ angstroms), and data were obtained from single scans in the range of $2 \theta$ from 5 to $40^{\circ}$ (with steps of $0.02^{\mathrm{O}}$ ) at room temperature.

\subsection{Data presentation}

The results of all analyses are reported as the average value of three replicates with standard deviation.

\section{Results and discussion}

\subsection{Characterization of the bulk lipid mixtures: choice of a lipid matrix to produce the lipid microparticles}

The WAXD data obtained for bulk pure stearic acid, pure cupuacu butter and the mixtures of SA and $\mathrm{CB}$ are presented in Figure 2. In the region of the low values of $2 \theta$ in the stearic acid diffractogram, peaks appear at 1.33 and $0.80 \mathrm{~nm}$, which is typical of this fatty acid (Teixeira, Garcia, Ilharco, Goncalves da Silva, \& Fernandes, 2010). It is important to emphasize that the polymorphism of carboxylic acids is different from that of triacylglycerols. Normal saturated fatty acids exhibit complex polymorphic behavior, and the crystal forms can exist in four different polymorphs: A, B, C and E (Bunjes \& Unruh, 2007; Moreno et al., 2007; Timms, 1984). Only the C form grows upon crystallization from the melt, and this form has also been found in the preparation of stearic acid nanoparticles. This polymorph has a typical orthorhombic subcell that is quite similar to the $\beta^{\prime}$-form of the triacylglycerols, as does form B (Bunjes \& Unruh, 2007; Timms, 1984). The peaks obtained in this study for pure stearic acid at 0.42 and $0.38 \mathrm{~nm}$ are in accord with this information. As expected, pure cupuacu butter presented an amorphous characteristic with peaks at $0.46 \mathrm{~nm}$ and $0.38 \mathrm{~nm}$. The amorphous region between $2 \theta$ of 16 and $25^{\mathrm{O}}$ likely hides a peak at $0.42 \mathrm{~nm}$. The peak at $0.46 \mathrm{~nm}$ is an indication of the presence of the $\beta$-form, and the simultaneous appearance of peaks at 0.42 (probable) and $0.38 \mathrm{~nm}$ would indicate the concurrent presence of the $\beta^{\prime}$-form. The presence of the $\beta^{\prime}$-form in $\mathrm{CB}$ is extremely likely, as it is a natural fat composed of a mixture 
of several types of triacylglycerols (Timms, 1984).

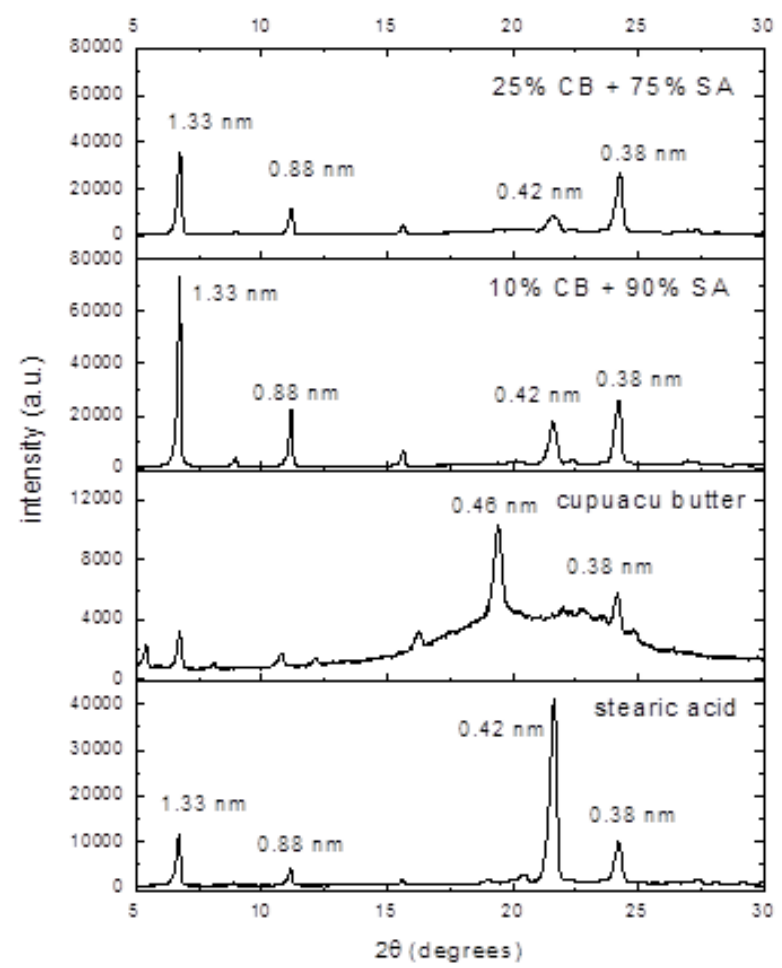

Figure 2: WAXD analyses of pure raw materials (stearic acid, SA, and cupuacu butter, CB) and bulk mixtures composed of SA and CB.

The addition of $\mathrm{CB}$ caused modifications in the peaks of pure SA and changed their intensities in both analyzed mixtures. The total absence of $\beta$ form in the lipid mixtures was expected, as the presence of SA did not allow for the presence of a highly organized crystalline arrangement. The increase in the intensities in the region of low values of $2 \theta$ suggests that the structure was altered by the stretching of the acyl chains, increasing the distance between the planes. In the "short-spacing" peaks region, pure stearic acid exhibited two very intense reflections at 0.42 and $0.38 \mathrm{~nm}$, linked to an orthorhombic structure (Timms, 1984). This structure was also observed with the addition of cupuacu butter, which caused a sharp decrease in the intensity of the reflection at $0.42 \mathrm{~nm}$ and diminished the intensity at $0.38 \mathrm{~nm}$. These decreases in the pure stearic acid diffractogram indicate that its original structure was significantly modified by the presence of cupuacu butter in the lipid matrix (Severino et al., 2011; Lin et al., 2007), although it is likely that the predominant crystalline structures were orthorhombic subcells. The disorganization of the lipid matrix induced by the presence of CB was also detected by the DSC data, as shown in Table 3.

From the obtained calorimetric data, it is clear that the addition of $10 \% \mathrm{CB}$ to stearic acid was able to decrease the CI to $75 \%$, and $25 \% \mathrm{CB}$ diminished the value to less than $60 \%$, indicating that the mixture of $\mathrm{CB}$ and $\mathrm{SA}$ was formed by a less ordered structure than pure stearic acid. A less ordered matrix favors an increasing number of voids in the structure. Therefore, it is able to accommodate a larger amount of encapsulated bioactive molecules, minimizing the expulsion of these molecules during storage and enabling control over their release (Muller et al., 2002).

Therefore, with the use of the data obtained by WAXD and DSC for the bulk lipid mixtures, it was concluded that the addition of only $10 \% \mathrm{CB}$ was enough to produce significant modifications in the structure of SA, creating a new lipid matrix with more imperfections in its structure. Such a high degree of disorganization could facilitate the encapsulation of bioactive molecules and increase their retention, which is highly desirable in the matrices chosen to produce solid lipid micro/nano particles (Severino et al., 2011; Attama, Schicke, \& Mueller-Goymann, 2006).

\subsection{Lipid microparticles: production, characterization and encapsulation of casein hydrolysate}

Preliminary studies were carried out with three formulations (10CB-2, 15CB-2 and 20CB-2, whose compositions are shown in Table 2) of empty LM to test their ability to produce microparticles. The results are presented in Figure 3.

In micrograph $3(\mathrm{~A})$, it can be observed that although the addition of $10 \% \mathrm{CB}$ was enough to change the structure of the bulk lipid matrix, it was not possible to form particles with this lipid composition when using $2 \%$ of surfactant to stabilize them. Apparently, the presence of $10 \% \mathrm{CB}$ did not decrease the crystallinity of the particles and did not produce spherical particles with $2 \%$ polysorbate 80 . The reduction in particle size first 
Table 3: Calorimetric data of stearic acid (SA), cupuacu butter (CB) and bulk lipid mixtures.

\begin{tabular}{ccccc}
\hline Formulation & $\begin{array}{c}\text { Onset temperature } \\
\left(\mathrm{T}_{0},{ }^{\circ} \mathrm{C}\right)\end{array}$ & $\begin{array}{c}\text { Melting peak } \\
\left(\mathrm{T}_{m},{ }^{\circ} \mathrm{C}\right)\end{array}$ & $\begin{array}{c}\text { Melting enthalpy } \\
\left.\left(\mathrm{J}^{-1}\right)^{-1}\right)\end{array}$ & CI (\%) \\
\hline Pure SA & 69.1 & 73.4 & 224.0 & - \\
$10 \% \mathrm{CB}+90 \% \mathrm{SA}$ & 67.1 & 69.4 & 196.0 & 78.7 \\
$25 \% \mathrm{CB}+75 \% \mathrm{SA}$ & 66.0 & 69.8 & 177.7 & 59.5 \\
\hline
\end{tabular}

causes an increase in the curvature of the surface and then increases the number of lipid molecules interacting with the surfactant. Thus, such an increase necessitates a higher concentration of surfactant molecules to stabilize the particulate system (Weiss et al., 2008).

Therefore, tests using lipid matrices containing 15 and $20 \% \mathrm{CB}$ were conducted. Their cumulative distributions were obtained and are presented in Figure 4.

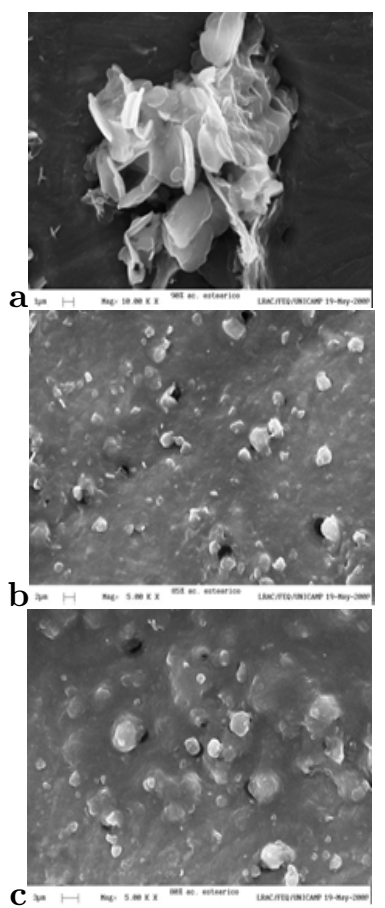

Figure 3: Scanning electron micrographs of empty lipid microparticles: (a) 10CB-2 (10,000x); (b) 15CB-2 (5,000x); (c) 20CB-2 (5,000x).

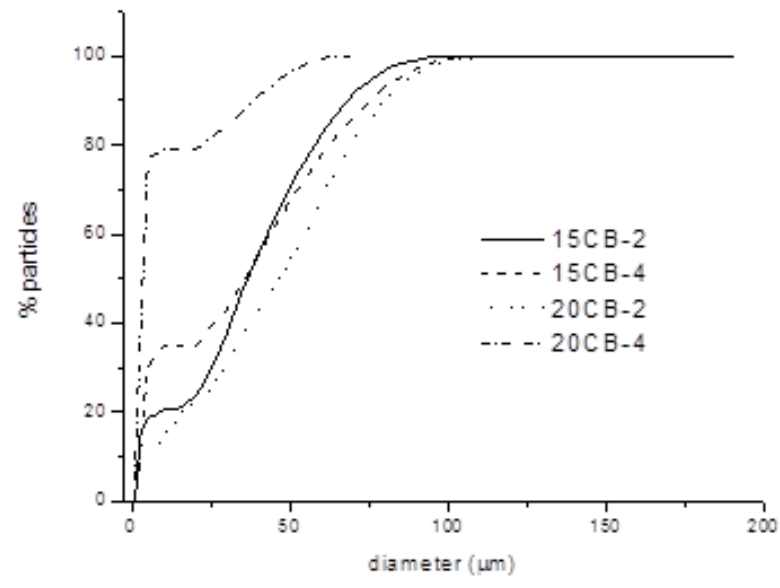

Figure 4: Particle size cumulative distributions for the different formulations used to produce empty lipid microparticles with mixtures of cupuacu butter and stearic acid.

The size distributions in Figure 4 indicate that the best choice for producing LM with lower average diameter values was the formulation in which 20 $\% \mathrm{CB}+80 \% \mathrm{SA}$ was stabilized with $4 \%$ polysorbate 80 because in this case, $80 \%$ of the particles had diameters below $10 \mu \mathrm{m}$ (66\% of the population had diameters between 2.1 and $5.0 \mu \mathrm{m}$ ). Therefore, using this particle formulation, casein hydrolysate was incorporated into the dispersions, resulting in an encapsulation efficiency of $73.9 \pm 4.5$ $\%$. This value was considered extremely satisfactory and was comparable to the results obtained by Barbosa et al. (2004), who also worked with the encapsulation of casein hydrolysates in lipid microparticles of stearic acid.

However, when comparing the size distributions of empty and casein hydrolysate-loaded LM as depicted in Figure 5, it is clear that the incorporation of casein hydrolysate changed the characteristics of the dispersions dramatically. This increase in size 
may be due to the peptides adsorbed around the LM, as Hyprol 8052 is surface-active (Mendanha et al., 2009). These nonencapsulated, adsorbed molecules were probably not separated by the ultrafiltration process; instead, they remained in the system around the particles and may have contributed to the morphological change visible via SEM.

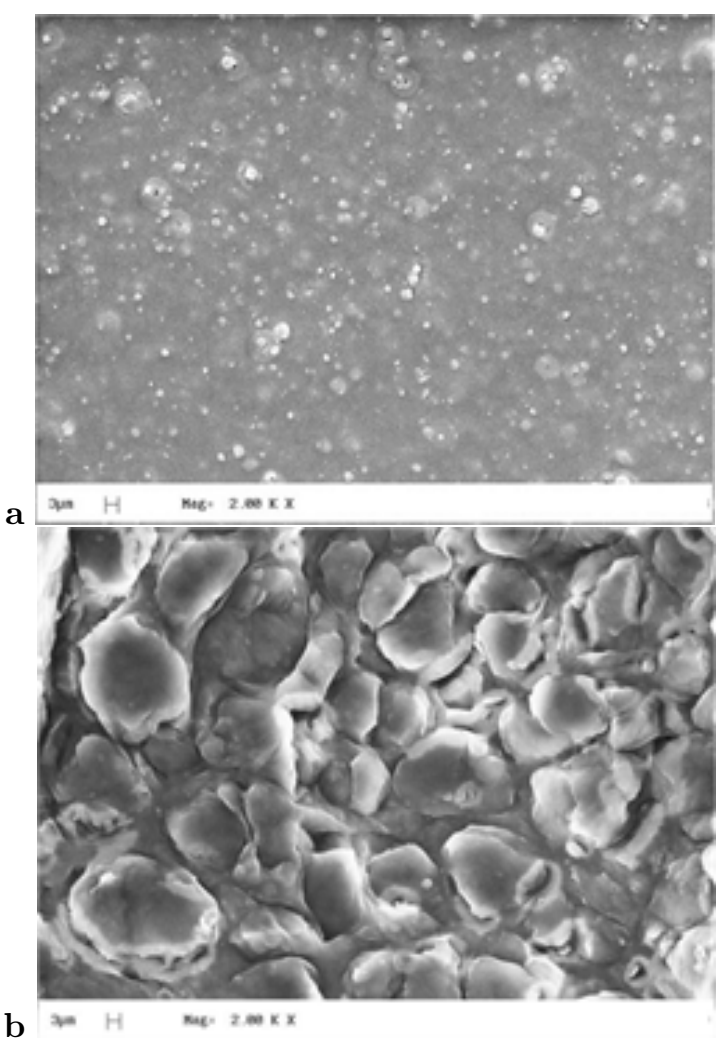

Figure 5: Micrographs obtained by SEM: (a) empty lipid microparticles; (b) lipid microparticles encapsulating casein hydrolysate (magnification: 2000x, both micrographs). Both systems were produced using formulation 20CB-4.

Figure 6 presents the thermograms obtained for empty and casein hydrolysate-loaded LM. It is clear that the thermal behavior was not altered by the presence of the encapsulated peptides. Due to the heterogeneous composition of the particles, the melting process began at $40{ }^{\circ} \mathrm{C}$, and the melting peak temperature was recorded as $65.2^{\circ} \mathrm{C}$, which guarantees that the microparticles produced are solid at the temperatures chosen for storage.

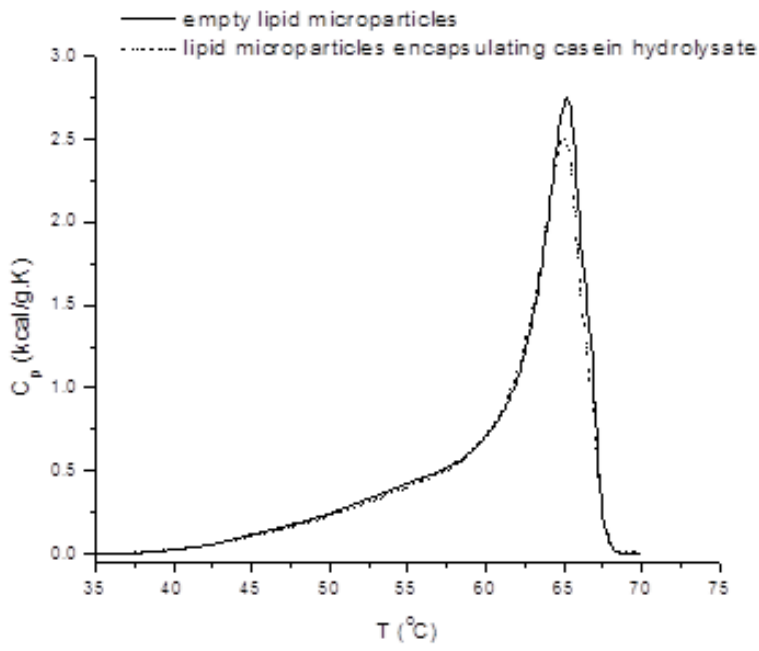

Figure 6: Thermograms obtained by DSC for fresh lipid microparticles. Both systems were produced using formulation 20CB-4.

To verify the behavior of LM over the storage period, the dispersions were stored at two different temperatures (refrigerated, between 7 and $10^{\circ} \mathrm{C}$, and at $25{ }^{\circ} \mathrm{C}$ ). The collected data showed that the final amount of liberated hydrolysate was the same under the different storage conditions, at approximately $25-30 \%$ of the initial mass of casein hydrolysate present in the system. The only difference was that at the end of the first week of storage, the samples stored at $25^{\circ} \mathrm{C}$ had already liberated $30 \%$ of their initial amounts of casein hydrolysate, whereas the samples under refrigeration had released approximately $10 \%$.

The size distribution of the LM was also monitored over the storage period, and the results of this monitoring are presented in Figure 7 . Under storage at $25^{\circ} \mathrm{C}$, the population with average sizes up to $70 \mu \mathrm{m}$ increased significantly, exhibiting a tendency for their particles to break or, more probably, to decrease in average size due to the liberation of the peptides on their surfaces. The size distribution of the LM stored under refrigeration did not appear to change significantly; however, the high standard deviation values in the population with average sizes up to $70 \mu \mathrm{m}$ may be due to the same phenomenon of peptide desorption on the LM surface. 


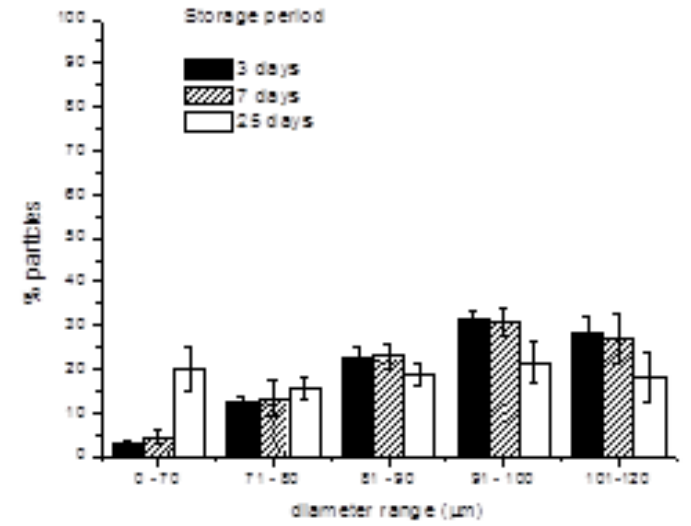

a

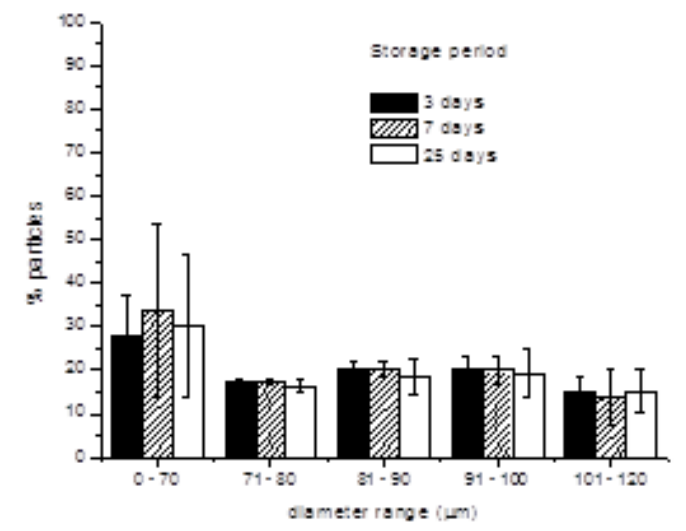

Figure 7: Particle size distribution of lipid particles encapsulating casein hydrolysate over a storage period of 25 days: (a) at room temperature; (b) under refrigeration. (Average of 3 samples \pm SD).

\section{Conclusions}

The data obtained in this study have shown that it is feasible to produce solid lipid microparticles of cupuacu butter and stearic acid to encapsulate casein hydrolysate. It was possible to select a suitable lipid mixture of both lipids using a minimum of $10 \% \mathrm{CB}$, according to the DSC and WAXD data; with this mixture, lipid microparticles stabilized with $4 \%$ polysorbate 80 were produced. The encapsulation efficiency obtained was high, at approximately $74 \%$. The thermal behavior was not altered by the presence of casein hydrolysate, but the morphology was modified, likely due to the adsorption of peptides on the surface of the particles.
After 25 days of storage, $30 \%$ of the initial amount of casein hydrolysate was liberated, probably from the adsorbed peptides, rather than from the encapsulated casein. More studies are necessary to investigate the extent of this adsorption and its implications for the stability of the dispersions over a longer period of storage.

\section{Acknowledgements}

The authors thank FAPESP for the scholarship (process 2007/05711-1, J.C.S.), Kerry do Brasil for the donation of Hyprol 8052, Prof. Lisandro P. Cardoso (IFGW/Unicamp) for the WAXD analyses and Ednelí Monterrey-Quintero for the laser diffraction measurements.

\section{References}

Agyei, D., \& Danquah, M. K. (2012). Rethinking food-derived bioactive peptides for antimicrobial and immunomodulatory activities. Trends in Food Science \& Technology, 23(2), 62-69. doi:\{10.1016/j.tifs. 2011.08. $010\}$

Almeida, A. J., \& Souto, E. (2007). Solid lipid nanoparticles as a drug delivery system for peptides and proteins. Advanced Drug Delivery Reviews, 59(6), 478-490. doi:\{10.1016/j. addr.2007.04.007\}

AOCS. (1998). Official Methods and Recommended Practices of the American Oil Chemists' Society. 5th ed., Champaign: AOCS Press.

Attama, A. A., Schicke, B. C., \& MuellerGoymann, C. C. (2006). Further characterization of theobroma oil-beeswax admixtures as lipid matrices for improved drug delivery systems. European Journal of Pharmaceutics and Biopharmaceutics, 64(3), 294-306. doi: $\{10.1016 /$ j.ejpb.2006.06.010\}

Barbosa, C., Morais, H., Delvivo, F., Mansur, H., De Oliveira, M., \& Silvestre, M. (2004). Papain hydrolysates of casein: molecular weight profile and encapsulation in lipospheres. Journal of the Science of Food and Agriculture, $84(14), 1891-1900$. doi: $\{10.1002 /$ jsfa. $1855\}$ 
Bunjes, H., \& Unruh, T. (2007). Characterization of lipid nanoparticles by differential scanning calorimetry, X-ray and neutron scattering. Advanced Drug Delivery Reviews, 59(6), 379-402. doi:\{10.1016/j.addr.2007.04.013\}

Cam, A., \& de Mejia, E. G. (2012). Role of dietary proteins and peptides in cardiovascular disease. Molecular Nutrition $\&$ Food Research, 56 (1), 53-66. doi:\{10.1002/mnfr.201100535\}

Clemente, A. (2000). Enzymatic protein hydrolysates in human nutrition. Trends in Food Science Technology, 11(7), 254-262. doi:10.1016/S0924-2244(01)00007-3

Dai, C., Wang, B., \& Zhao, H. (2005). Microencapsulation peptide and protein drugs delivery system. Colloids and Surfaces BBiointerfaces, 41(2-3), 117-120. doi: $\{10$. 1016/j.colsurfb.2004.10.032\}

del Mar Contreras, M., Carron, R., Jose Montero, M., Ramos, M., \& Recio, I. (2009). Novel casein-derived peptides with antihypertensive activity. International Dairy Journal, 19(10), 566-573. doi:\{10.1016/j.idairyj.2009. $05.004\}$

Espeche Turbay, M. B., de Moreno de LeBlanc, A., Perdigon, G., Savoy de Giori, G., \& Hebert, E. M. (2012). beta-Casein hydrolysate generated by the cell envelope-associated proteinase of Lactobacillus delbrueckii ssp lactis CRL 581 protects against trinitrobenzene sulfonic acid-induced colitis in mice. Journal of Dairy Science, 95(3), 1108-1118. doi:\{10. $3168 /$ jds.2011-4735\}

Fathi, M., Mozafari, M. R., \& Mohebbi, M. (2012). Nanoencapsulation of food ingredients using lipid based delivery systems. Trends in Food Science \& Technology, 23(1), 13-27. doi: $\{10$. 1016/j.tifs.2011.08.003\}

Favaro-Trindade, C. S., Santana, A. S., MonterreyQuintero, E. S., Trindade, M. A., \& Netto, F. M. (2010). The use of spray drying technology to reduce bitter taste of casein hydrolysate. Food Hydrocolloids, 24(4), 336340. doi: $\{10.1016 / j$. foodhyd.2009.10.012\}

Gauthier, S. F., Pouliot, Y., \& Saint-Sauveur, D. (2006). Immunomodulatory peptides obtained by the enzymatic hydrolysis of whey proteins. International Dairy Journal, 16(11), 1315-1323. doi:\{10.1016/j.idairyj . 2006.06.014\}
Hartmann, R., \& Meisel, H. (2007). Food-derived peptides with biological activity: from research to food applications. Current Opinion in Biotechnology, 18(2), $163-169$. ¡ce:title¿Plant biotechnology / Food biotechnologyi/ce:title ¿. doi:10.1016/j.copbio.2007. 01.013

Junyaprasert, V. B., Teeranachaideekul, V., Souto, E. B., Boonme, P., \& Mueller, R. H. (2009). $\mathrm{Q}(10)$-loaded NLC versus nanoemulsions: Stability, rheology and in vitro skin permeation. International Journal of Pharmaceutics, 377(1-2), 207-214. doi:\{10.1016/j. ijpharm.2009.05.020\}

Kitts, D., \& Weiler, K. (2003). Bioactive proteins and peptides from food sources. Applications of bioprocesses used in isolation and recovery. Current Pharmaceutical Design, 9(16), 1309-1323. doi:\{10.2174/ $1381612033454883\}$

Korhonen, H. (2009). Milk-derived bioactive peptides: From science to applications. Journal of Functional Foods, 1(2), 177-187. doi:\{10. 1016/j.jff.2009.01.007\}

Lairon, D. (2009). Digestion and absorption of lipids. In: McClements, D.J.; Decker, E.A. (Eds). Designing functional foods. CRC Press, Boca Raton: FL, USA, p. 66-93.

Lannes, S. C. S., Medeiros, M. L., \& Gioielli, L. A. (2004). Rheological properties of cupuassu and cocoa butters. Grasas y Aceites, 2(2), 115-121.

Lee, Y. H., \& Yamamoto, A. (1989). Penetration and enzymatic barriers to peptide and protein absorption. Advanced Drug Delivery Reviews, 4(2), 171-207.

Lin, X., Li, X., Zheng, L., Yu, L., Zhang, Q., \& Liu, W. (2007). Preparation and characterization of monocaprate nanostructured lipid carriers. Colloids and Surfaces A-Physicochemical and Engineering Aspects, 311(1-3), 106-111. doi:\{10.1016/j.colsurfa.2007.06.003\}

Lopez Exposito, I., \& Recio, I. (2006). Antibacterial activity of peptides and folding variants from milk proteins. International Dairy Journal, 16(11), 1294-1305. doi:\{10.1016/j. idairyj.2006.06.002\}

McClements, D. J. (2010). Design of NanoLaminated Coatings to Control Bioavailability of Lipophilic Food Components. Journal 
of Food Science, 75(1), R30-R42. doi:\{10 . $1111 / \mathrm{j} .1750-3841.2009 .01452 . x\}$

McClements, D. J., \& Li, Y. (2010). Structured emulsion-based delivery systems: Controlling the digestion and release of lipophilic food components. Advances in Colloid and Interface Science, 159(2), 213-228. doi:\{10.1016/ j.cis.2010.06.010\}

Mehnert, W, \& Mader, K. (2001). Solid lipid nanoparticles - Production, characterization and applications. Advanced Drug Delivery Reviews, 47(2-3), 165-196. doi:\{10.1016/ S0169-409X(01)00105-3\}

Mendanha, D. V., Molina Ortiz, S. E., FavaroTrindade, C. S., Mauri, A., MonterreyQuintero, E. S., \& Thomazini, M. (2009). Microencapsulation of casein hydrolysate by complex coacervation with SPI/pectin. Food Research International, 42(8), 1099-1104. doi: $\{10.1016 /$ j.foodres.2009.05.007\}

Mercier, A, Gauthier, S., \& Fliss, L. (2004). Immunomodulating effects of whey proteins and their enzymatic digests. International Dairy Journal, 14(3), 175-183. doi:\{10 . 1016/j.idairyj.2003.08.003\}

Mikkelsen, T., Rasmussen, E, Olsen, A, Barkholt, V, \& Frokiaer, H. (2006). Immunogenicity of kappa-casein and glycomacropeptide. Journal of Dairy Science, 89(3), 824-830.

Molina Ortiz, S. E., Mauri, A., MonterreyQuintero, E. S., Trindade, M. A., Santana, A. S., \& Favaro-Trindade, C. S. (2009). Production and properties of casein hydrolysate microencapsulated by spray drying with soybean protein isolate. $L W T$-Food Science and Technology, 42(5), 919-923. doi: $\{10.1016 / \mathrm{j}$. lwt.2008.12.004\}

Moreno, E., Cordobilla, R., Calvet, T., CuevasDiarte, M. A., Gbabode, G., Negrier, P., .. Oonk, H. A. J. (2007). Polymorphism of even saturated carboxylic acids from ndecanoic to n-eicosanoic acid. New Journal of Chemistry, 31(6), 947-957. doi:\{10.1039/ b700551b\}

Moutinho, C. G., Matos, C. M., Teixeira, J. A., \& Balcao, V. M. (2012). Nanocarrier possibilities for functional targeting of bioactive peptides and proteins: state-of-the-art. Journal of Drug Targeting, 20(2), 114-141. doi:\{10. 3109/1061186X.2011.628397\}
Muller, R., Radtke, M, \& Wissing, S. (2002). Solid lipid nanoparticles (SLN) and nanostructured lipid carriers (NLC) in cosmetic and dermatological preparations. Advanced Drug Delivery Reviews, 54(1), S131-S155. Conference on Human Skin - the Medium of Touch, ST REMY DE PROVENCE, FRANCE, JUN 13-15, 2002. doi:\{10.1016/ S0169-409X(02)00118-7\}

Muller, R., Mader, K, \& Gohla, S. (2000). Solid lipid nanoparticles (SLN) for controlled drug delivery - a review of the state of the art. European Journal of Pharmaceutics and Biopharmaceutics, 50(1), 161-177. doi:\{10. 1016/S0939-6411(00)00087-4\}

Nakamura, T., Mizutani, J., Ohki, K., Yamada, K., Yamamoto, N., Takeshi, M., \& Takazawa, K. (2011). Casein hydrolysate containing ValPro-Pro and Ile-Pro-Pro improves central blood pressure and arterial stiffness in hypertensive subjects: A randomized, doubleblind, placebo-controlled trial. Atherosclerosis, 219(1), 298-303. doi: $\{10.1016 / \mathrm{j}$. atherosclerosis.2011.06.007\}

Osborn, H. T., \& Akoh, C. C. (2002). Structured lipids - novel fats with medical, nutraceutical and food applications. Comprehensive Reviews in Food Science and Food Safety, 1, 93-103.

Pan, Y., Lee, A., Wan, J., Coventry, M. J., Michalski, W. P., Shiell, B., \& Roginski, H. (2006). Antiviral properties of milk proteins and peptides. International Dairy Journal, 16(11), 1252-1261. doi:\{10.1016/j.idairyj . 2006.06.010\}

Peterson, G. (1979). Review of the foline phenol protein quantitation method of lowry, rosebrough, farr and randall. Analytical Biochemistry, 100(2), 201-220. doi:\{10.1016/ 0003-2697(79)90222-7\}

Saraiva, S. A., Cabral, E. C., Eberlin, M. N., \& Catharino, R. R. (2009). Amazonian Vegetable Oils and Fats: Fast Typification and Quality Control via Triacylglycerol (TAG) Profiles from Dry Matrix-Assisted Laser Desorption/Ionization Time-of-Flight (MALDITOF) Mass Spectrometry Fingerprinting. Journal of Agricultural and Food Chemistry, 57(10), 4030-4034. doi:\{10.1021/jf900043u\} 
Severino, P., Pinho, S. C., Souto, E. B., \& Santana, M. H. A. (2011). Polymorphism, crystallinity and hydrophilic-lipophilic balance of stearic acid and stearic acid-capric/caprylic triglyceride matrices for production of stable nanoparticles. Colloids and Surfaces BBiointerfaces, 86(1), 125-130. doi:\{10.1016/ j.colsurfb.2011.03.029\}

Shaji, J., \& Patole, V. (2008). Protein and Peptide Drug Delivery: Oral Approaches. Indian Journal of Pharmaceutical Sciences, 70(3), 269-277.

Silva, J. C., Plivelic, T. S., Herrera, M. L., Ruscheinsky, N., Kieckbusch, T. G., Luccas, V., \& Torriani, I. L. (2009). Polymorphic Phases of Natural Fat from Cupuassu (Theobroma grandiflorum) Beans: A WAXS/SAXS/DSC Study. Crystal Growth \& Design, 9(12), 5155-5163. doi:\{10. $1021 / \mathrm{cg} 901081 \mathrm{j}\}$

Teixeira, A. C. T., Garcia, A. R., Ilharco, L. M., Goncalves da Silva, A. M. P. S., \& Fernandes, A. C. (2010). Phase behaviour of oleanolic acid, pure and mixed with stearic acid: Interactions and crystallinity. Chemistry and Physics of Lipids, 163(7), 655-666. doi:\{10. 1016/j.chemphyslip.2010.06.001\}

Timms, R. (1984). Phase-behavior of fats and their mixtures. Progress in Lipid Research, 23(1), 1-38. doi: $\{10.1016 / 0163-7827(84) 90004-3\}$

Weiss, J., Decker, E. A., McClements, D. J., Kristbergsson, K., Helgason, T., \& Awad, T. (2008). Solid lipid nanoparticles as delivery systems for bioactive food components. Food Biophysics, 3(2), 146-154. 2nd International Symposium on Delivery of Functionality in Complex Food Systems, Univ Mass, Amherst, MA, OCT 08-10, 2007. doi: $\{10$. 1007/s11483-008-9065-8\}

Yokota, D., Moraes, M., \& Pinho, S. C. (2012). Characterization of lyophilized liposomes produced with non-purified soy lecithin: A case study of casein hydrolysate microencapsulation. Brazilian Journal of Chemical Engineering, 29(2), 325-335. 